\title{
Hiatus hernia in a 6-year-old boy: A rare presentation
}

\section{Gajendra Vikram Singh, Ajay Kumar Verma', Mayank Mishra ${ }^{2}$, Santosh Kumar, Ved Prakash', Surya Kant ${ }^{1}$, Virendra Kumar ${ }^{3}$, Ankit Bhatia ${ }^{1}$}

Department of TB and Chest Diseases, SN Medical College, Agra, 'Department of Pulmonary Medicine, King George's Medical University, Lucknow, ${ }^{3}$ Department of Medicine, M.R.A. Medical College, Ambedkar Nagar, Uttar Pradesh, ${ }^{2}$ Department of Pulmonary Medicine, All India Institute of Medical Sciences, Rishikesh, Uttarakhand, India

Address for the Correspondence: Dr. Ajay Kumar Verma, Department of Pulmonary Medicine, King George's Medical University, Lucknow, Uttar Pradesh, India. E-mail: drajay21@gmail.com

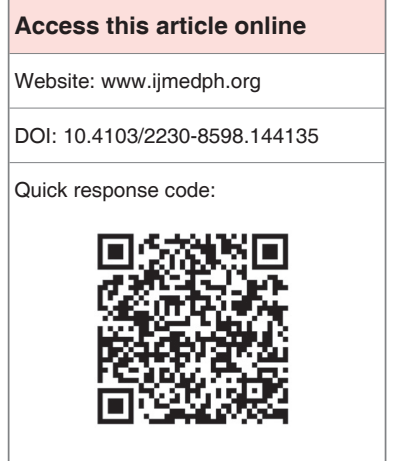

Hiatus hernia refers to upward displacement of the stomach through the diaphragmatic esophageal hiatus into the thoracic cavity. It is rare in children and may be asymptomatic or may present with various symptoms. We are reporting a case of sliding hiatus hernia detected incidentally in a 6 year old boy.

Key words: Barium swallow, chest radiograph, computed tomography scan, hiatus hernia

\section{INTRODUCTION}

In hiatus hernia abdominal viscera push up into thoracic cavity through the esophageal hiatus. In 1926, Akerlund et al. ${ }^{[1]}$ have reported that hiatal hernia was found in $2.3 \%$ of all upper gastrointestinal $\mathrm{X}$-ray studies. With the improvement of radiographic techniques and a more systematic approach to their detection, more hernias were identified, such that by 1955 the reported incidence was 15\%. Incidence of hiatal hernias increases with age; approximately $60 \%$ of individuals aged 50 or older have a hiatal hernia. ${ }^{[4]}$ It is a rare condition in the pediatric age group, which may be asymptomatic or it may present with a variety of symptoms or complications. ${ }^{[6,7]}$ We report a case of sliding hiatus hernia incidentally in a 6 year old boy.

\section{CASE REPORT}

A 6-year-old boy presented with the complaints of dyspnea, failure to thrive, off and on vomiting and left sided multiple scars in the region of left lateral chest wall with history of multiple attempts of pleural aspirations and an attempt of intercostal tube insertion [Figure 1a].

On examination, the boy was of poor built and malnourished. There were diminished movements in left hemithorax. On auscultation, there were diminished breath sounds in left hemithorax along with positive succession splash sign. On investigation, except anemia and decreased serum albumin, rest of the biochemical parameters was within normal limits.

The postero-anterior chest radiograph revealed a fluid-filled cavitary lesion in the left hemithorax with ipsilateral collapse of lung with contra lateral mediastinal shift [Figure 1b]. On left lateral chest radiograph, there were two fluid levels [Figure 1c]. The boy underwent a barium swallow study, which showed herniation of the gastro-esophageal junction and entire stomach into thoracic cavity [Figure 2]. Subsequently, non-contrast and contrast enhanced computed tomography (CT) of the chest and upper abdomen confirmed these findings [Figures 3a-c]. There was no history suggestive of hiatus hernia or gastro-esophageal reflux disease in other family members. Medical management was given but patient did not improve so he was referred for corrective surgery but patient refused for surgery.

\section{DISCUSSION}

The term hiatus hernia was proposed in 1926 by Akerlund et al. ${ }^{[1]}$ Hiatus hernia is herniation of abdominal viscera into the thoracic cavity through the oesophageal hiatus. ${ }^{[9]}$ The incidence of hiatus hernia increases significantly with age and it occurs in about $10 \%$ of the adult population. ${ }^{[8]}$ Children with this condition usually have it since birth (congenital). Some cases may have an autosomal dominant type of inheritance. ${ }^{[3]}$ There are four major types of hiatus hernias. The most common one 


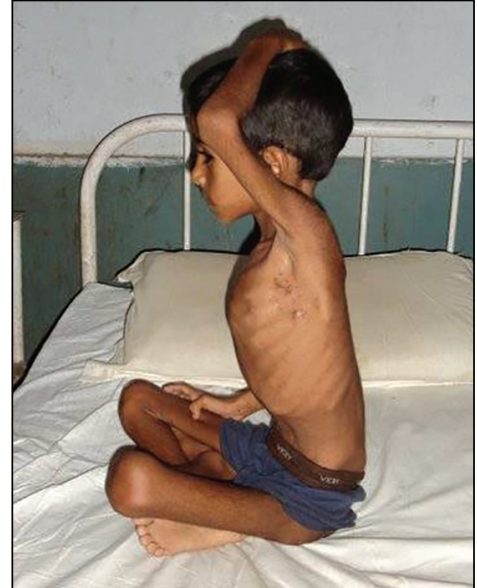

Figure 1a: Multiple scars in lateral chest wall

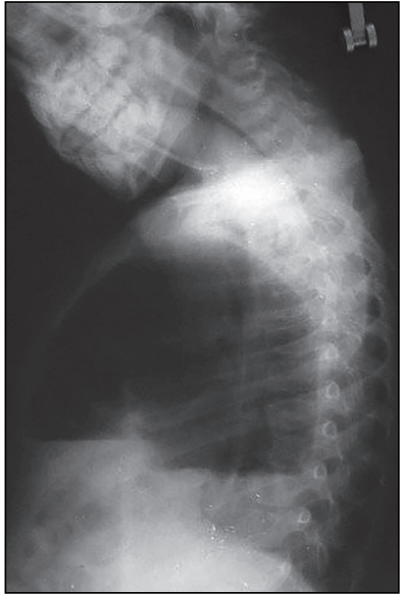

Figure 1c: Lateral view showing 2 air fluid interfaces

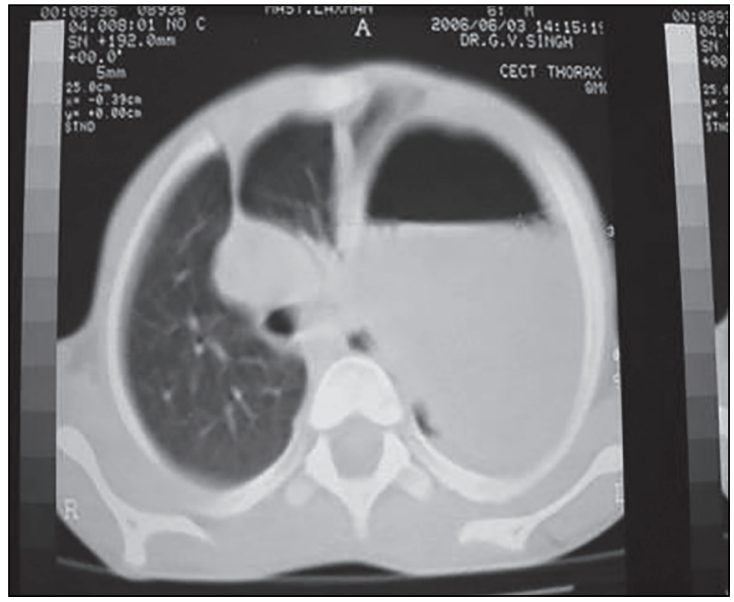

Figure 3a: Computed tomography scan confirming findings of barium study

is Type I (sliding) hernia, in which the gastro-esophageal junction with a portion of stomach herniates into the thoracic cavity. In a Type II (Rolling or para-esophageal) hernia, the gasto-esophageal junction remains at or below the level of diaphragm and the gastric fundus herniates superiorly in a para-esophageal location. Type

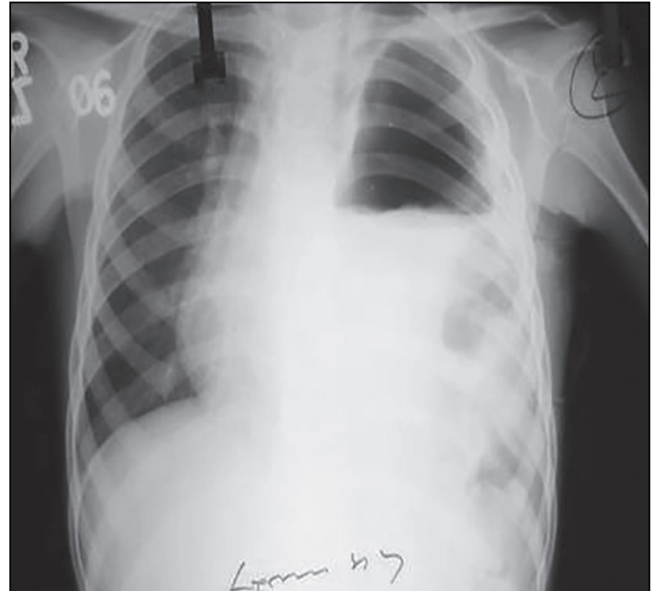

Figure 1b: Chest X-ray (PA) view showing air fluid level

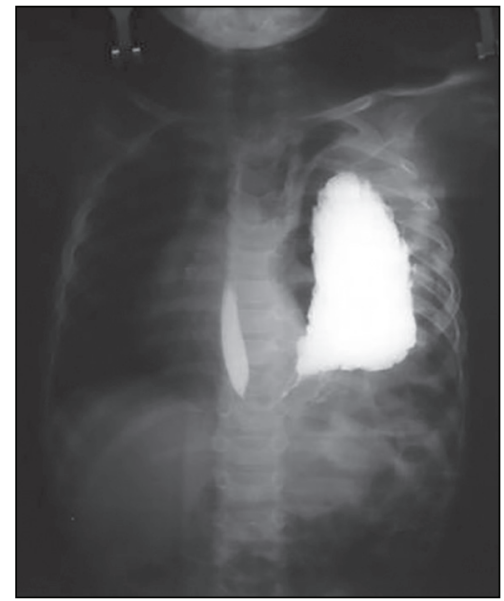

Figure 2: Barium swallow study herniation of whole stomach into thoracic cavity

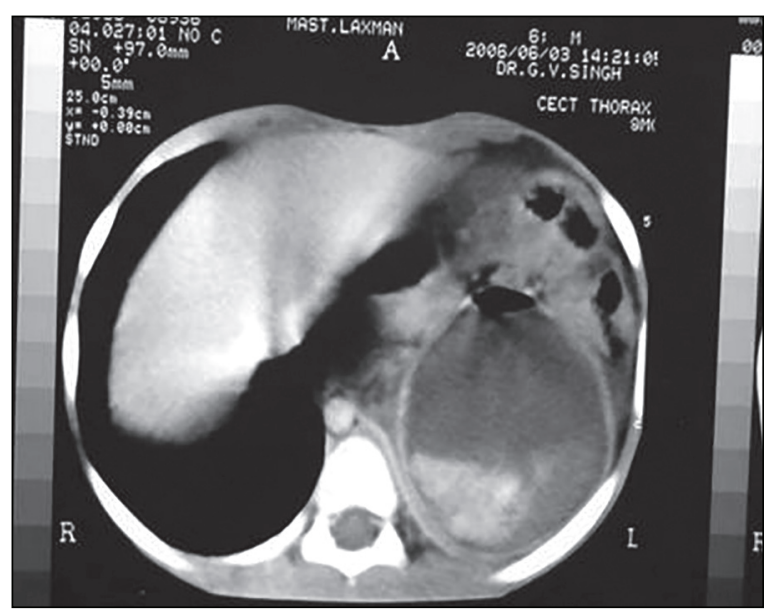

Figure 3b: Computed tomography scan confirming findings of barium study

III hernia has features of both Type I and Type II hernias and it is more common than Type II. In Type IV hernias, all or part of the stomach herniates into the thorax, usually with organo-axial rotation of the stomach. ${ }^{[2]}$ 


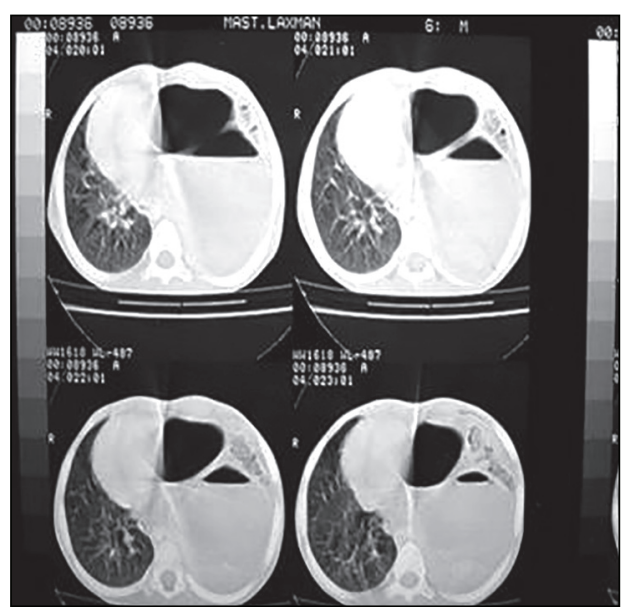

Figure 3c: Computed tomography scan confirming findings of barium study

Hiatus hernia may be asymptomatic and discovered incidentally on routine chest radiographs or CT scans performed for other purposes. While symptomatic, patients present with epigastric pain, heartburn, nausea, vomiting and regurgitation. ${ }^{[11]}$ Giant hiatus hernias can strangulate, leading to anemia or overt bleeding, and other symptoms such as chest pain or breathlessness after meals. ${ }^{[5,6]}$ Barium swallow examination, upper gastro-intestinal endoscopy and CT are routinely used to confirm the diagnosis of hiatus hernia. In addition, manometry, $24 \mathrm{~h} \mathrm{pH}$ testing and gastric scintigraphy are used for pre-operative evaluation. ${ }^{[2]}$ Medical management includes antacids, $\mathrm{H} 2$ receptor antagonists and proton pump inhibitors (PPIs). PPIs afford the highest levels of symptomatic relief. ${ }^{[10]}$ Patients who are refractory or have inadequate control with PPI therapy are considered for laparoscopic Nissen fundoplication. ${ }^{[2]}$ The purpose of this case report is to draw attention to the fact that, although rare, hiatus hernia should be considered in the differential diagnosis of hydropneumothorax.

\section{REFERENCES}

1. Akerlund A, Onnell H, Key E. Hernia diaphragmatica hiatus oesophagei vom anastomishen und roentgenologischen gesichtspunkt. Acta Radiol 1926;6:3-22.

2. Canon CL, Morgan DE, Einstein DM, Herts BR, Hawn MT, Johnson LF. Surgical approach to gastroesophageal reflux disease: What the radiologist needs to know. Radiographics 2005;25:1485-99.

3. Carré IJ, Johnston BT, Thomas PS, Morrison PJ. Familial hiatal hernia in a large five generation family confirming true autosomal dominant inheritance. Gut 1999;45:649-52.

4. Goyal RK. Diseases of the esophagus. Harrison's Principles of Internal Medicine. 17th ed., Ch. 286. McGraw Hill Professional: 2009.

5. Herek O, Yildiran N. A massive hiatal hernia that mimics a congenital diaphragmatic hernia. An unusual presentation of hiatal hernia in childhood: Report of a case. Surg Today 2002;32:1072-4.

6. Karpelowsky JS, Wieselthaler N, Rode H. Primary paraesophageal hernia in children. J Pediatr Surg 2006;41:1588-93.

7. Rajesh MU, Prasad LC. Hiatus hernia in a ten year old boy. Med J Armed Forces India 2008;64:189-90.

8. Siu CW, Jim MH, Ho HH, Chu F, Chan HW, Lau CP, et al. Recurrent acute heart failure caused by sliding hiatus hernia. Postgrad Med J 2005;81:268-9.

9. Stylopoulos N, Rattner DW. The history of hiatal hernia surgery: From Bowditch to laparoscopy. Ann Surg 2005;241:185-93.

10. Tutuian R, Castell DO. Gastroesophageal reflux disease: Natural history and long-term medical and surgical outcomes. Clin Cornerstone 2003;5:51-7.

11. Yazici M, Karaca I, Etensel B, Temir G, Günsar C, Güçlü C, et al. Paraesophageal hiatal hernias in children. Dis Esophagus 2003;16:210-3.

How to cite this article: Singh GV, Verma AK, Mishra M, Kumar S, Prakash V, Kant S, et al. Hiatus hernia in a 6-year-old boy: A rare presentation. Int J Med Public Health 2014;4:514-6.

Source of Support: Nil, Conflict of Interest: None declared. 